\title{
PENINGKATAN HASIL BELAJAR MATEMATIKA TENTANG LUAS PERMUKAAN DAN VOLUME BANGUN RUANG SISI DATAR DENGAN MODEL PEMBELAJARAN TEAM ASSISTED INDIVIDUALIZATION
}

\author{
Sarjono $^{1}$ \\ SMK Negeri 4 Pangkalpinang, Jl Raya Pasir Ketapang, Temberan, Bukit Intan, Kota Pangkalpinang ${ }^{1}$ \\ e-mail: sarjonopkppbb@gmail.com
}

\begin{abstract}
ABSTRAK
Hasil belajar matematika masih jauh dari yang diharapkan karena banyak siswa yang memperoleh nilai di bawah Kriteria Ketuntasan Minimun (KKM) yang telah ditentukan. Hal ini menjadi tantangan bagi guru untuk mengembangkan model pembelajaran yang lebih menyenangkan dan mudah dipahami. Penelitian ini bertujuan untuk mengetahui peningkatan hasil belajar matematika tentang luas permukaan dan volume bangun ruang sisi datar menggunakan model pembelajaran kooperatif tipe Team Assisted Individualization (TAI). TAI merupakan salah satu model pembelajaran untuk membuat siswa aktif dan menyenangkan. Pada model pembelajaran ini siswa diminta memecahkan masalah dengan bantuan temannya atau yang biasa disebut tutor. Penelitian ini melibatkan 21 siswa kelas XI AP SMK Negeri 4 Pangkalpinang Provinsi Bangka Belitung Tahun Pelajaran 2015/2016. Indikator keberhasilan diukur dengan membandingkan antara sebelum dan sesudah menerapkan TAI. Hasil penelitian menunjukkan model pembelajaran kooperatif tipe TAI dapat membangkitkan respon siswa yang ditunjukkan dengan meningkatnya keaktifan dan kegairahan belajar siswa khususnya saat menjawab pertanyaan yang diajukan. Peningkatan keberhasilan siswa dapat dilihat dalam setiap siklusnya. Hasil belajar pada pra-siklus, siklus 1 , dan siklus 2 masing-masing didapatkan nilai rata-rata hasil belajar secara berturut-turut adalah 55,90; 62,57; dan 74,48. Peningkatan ini berkorelasi positif dengan kenaikan persentase ketuntasan siswa secara klasikal untuk ketiga siklus, yaitu 28,57\%, 57,14\%, dan 80,95\%.
\end{abstract}

Kata kunci:

Hasil Belajar, Model Pembelajaran Kooperatif, Team Assisted Individualization, Luas Permukaan dan Volume Bangun Ruang Sisi Datar

\begin{abstract}
Mathematics learning outcomes are still far from expected because many students score below the predetermined minimum completeness criteria. This is becomes a challenge for teachers to develop learning models that are more fun and easy to understand. This study aims to determine the increase in mathematics learning outcomes about the surface area and volume of flat-sided shapes using the Team Assisted Individualization (TAI) type cooperative learning model. TAI is a learning model to make students active and fun. In this learning model students are asked to solve problems with the help of friends or what is commonly called a tutor. This research involved 21 students of class XI AP SMK Negeri 4 Pangkalpinang Bangka Belitung Province on academic year 2015/2016. Success indicators are measured by comparing before and after implementing TAI. The results showed that the TAI type cooperative learning model can generate student responses as indicated by the increased activity and enthusiasm of student learning, especially when answering the questions asked. The increase in student success can be seen in each cycle. The learning outcomes in the pre-cycle, cycle 1, and cycle 2 obtained the average value of learning outcomes were 55.90; 62.57; and 74.48 respectively. This increase was positively correlated with an increase in the percentage of student completeness classically for the three cycles which are $28.57 \%, 57.14 \%$, and $80.95 \%$.
\end{abstract}

Keywords:

Learning Outcomes, Cooperative Learning Model, Team Assisted Individualization, Surface Area and Build Volume Flat Side 


\section{$\pi$ (Phi)}

\section{PENDAHULUAN}

Mengajar adalah membimbing belajar agar siswa mampu belajar. Aktivitas siswa sangat diperlukan karena siswalah yang seharusnya banyak aktif. Siswa sebagai subyek didik adalah yang merencanakan dan siswa sendiri yang melaksanakan belajar. Pada kenyataan, di sekolah-sekolah seringkali guru yang aktif sementara siswa tidak diberi kesempatan untuk aktif.

Pembelajaran matematika seharusnya tidak lagi fokus pada penyerapan melalui pencapaian informasi tetapi lebih mengutamakan pengembangan kemampuan dan pemrosesan informasi. Oleh karena itu aktivitas siswa perlu ditingkatkan melalui latihan-latihan atau tugas dengan bekerja dalam kelompok kecil dan menjelaskan ideide kepada orang lain.

Pembelajaran

matematika memerlukan partisipasi aktif dari siswa sehingga perlu adanya model pembelajaran yang melibatkan siswa secara langsung dalam pembelajaran. Pembelajaran yang dimaksud disini adalah pembelajaran kooperati yaitu pengajaran yang melibatkan siswa bekerja dalam kelompok-kelompok untuk menetapkan tujuan bersama.

Pembelajaran model kooperatif menekankan pada interaksi antar siswa. Siswa akan melakukan komunikasi aktif dengan sesama temannya. Dengan komunikasi diharapkan siswa dapat menguasai materi pelajaran dengan mudah karena siswa lebih mudah memahami penjelasan dari kawannya dibanding penjelasan dari guru, karena taraf pengetahuan serta pemikiran mereka lebih sejalan dan sepadan.

Kriteria Ketuntasan Minimal (KKM) mata pelajaran matematika kelas XI yang ditetapkan SMK Negeri 4 Pangkalpinang Provinsi Bangka Belitung tahun pelajaran 2015/2016 adalah 65. Artinya siswa dikatakan tuntas jika perolehan hasil belajar siswa minimal 65. Tetapi kondisi di kelas XI AP dalam kompetensi dasar luas permukaan dan volume bangun ruang sisi datar pada materi kubus dan balok masih belum memenuhi KKM seperti yang ditetapkan. Hal ini diperoleh dari data hasil pra tindakan yang dilakukan tanggal 22 April 2016.

Pembelajaran dilakukan dengan metode ceramah dan tanya jawab. Setelah pembelajaran dan evaluasi, diperoleh hasil belajar siswa dengan nilai rata-rata kelas 55,90 . Siswa yang mencapai KKM hanya 6 siswa $(28,57 \%)$ dari total keseluruhan 21 siswa. Kenyataan ini menunjukkan bahwa ketuntasan belajar siswa yang diperoleh di kelas XI AP masih rendah.

Salah satu alternatif pemecahan masalah tersebut adalah melakukan tindakan dengan menerapkan model pembelajaran kooperatif tipe TAI (Team Assisted Individualization). Model pembelajaran ini menuntut siswa untuk aktif mempelajari konsep melalui aktivitas pemecahan masalah, mengungkapkan ide-ide, melakukan diskusi, serta presentasi dalam kelompok sehingga setiap anggota kelompok memiliki peran dan tanggung jawab masing-masing. Dalam kegiatan belajar, masing-masing kelompok tidak ada siswa yang pasif dan tidak ada siswa yang tidak berkontribusi. Siswa secara individu dapat lebih percaya diri terutama dalam mengemukakan pendapat secara lisan. Dengan model pembelajaran kooperatif tipe TAI diharapkan dapat meningkatkan hasil belajar matematika tentang luas permukaan dan volume bangun ruang sisi datar.

Dari uraian diatas, penelitian ini melakukan upaya peningkatan hasil belajar matematika tentang luas permukaan dan volume bangun ruang sisi datar dengan model pembelajaran kooperatif tipe TAI pada siswa kelas XI AP SMK Negeri 4 Pangkalpinang Tahun 2016.

Penelitian ini diharapkan dapat memberikan manfaat secara teoritis berupa memperkaya ilmu pengetahuan tentang pembelajaran matematika dengan menggunakan model pembelajaran kooperatif tipe TAI yang dapat meningkatkan 


\section{$\pi$ (Phi)}

hasil belajar siswa dan dapat dijadikan bahan kajian bagi pengembang model pembelajaran siswa aktif yang dapat meningkatkan hasil belajar siswa. Manfaat praktis bagi peneliti adalah dapat dijadikan data masukan dalam pengembangan kreativitas dalam meneliti dengan model pembelajaran siswa aktif. Bagi siswa penelitian ini diharapkan dapat menumbuhkan jiwa kemandirian dalam belajar dan dapat menumbuhkan kreativitas siswa agar mendapatkan hasil belajar matematika yang maksimal.
Jurnal Pendidikan Matematika Volume 5 Nomor 2 Tahun 2021

\section{METODE PENELITIAN}

Subjek penelitian ini adalah siswa kelas XI AP SMK Negeri 4 Pangkalpinang Provinsi Bangka Belitung tahun pelajaran 2015/2016 sebanyak 21 siswa yang terdiri dari 8 laki-laki dan 13 perempuan. SMK ini beralamatkan di Jalan Raya Pasir Ketapang, Temberan, Bukit Intan, Kota Pangkalpinang.

Penelitian dilakukan tanggal 18 April 2016 sampai dengan 8 Juni 2016 (3 bulan) dengan jadwal penelitian seperti dapat dilihat pada Tabel 1.

Tabel 1. Jadwal Penelitian

\begin{tabular}{cll}
\hline No & \multicolumn{1}{c}{ Uraian kegiatan } & \multicolumn{1}{c}{ Waktu } \\
\hline 1 & Persiapan penelitian (perijinan) & 01 - 16 Apil 2016 \\
2 & Pelaksanaan dan pengolahan data pra siklus & 18 - 23 April 2016 \\
3 & Persiapan pelaksanaan siklus 1 & 20 - 23 April 2016 \\
4 & Pelaksanaan dan pengolahan data siklus 1 & 25 - 30 April 2016 \\
5 & Persiapan siklus 2 & 28 April - 7 Mei 2016 \\
6 & Pelaksanaan dan pengolahan data siklus 2 & 09 - 14 Mei 2016 \\
7 & Penyusunan laporan PTK & 25 April - 8 Juni 2016 \\
8 & Seminar & 09 November 2016 \\
9 & Pengesahan dan pembukuan di perpustakaan & 30 November 2016 \\
\hline
\end{tabular}

\section{Penelitian Tindakan Kelas}

Metode penelitian yang digunakan adalah Penelitian Tindakan Kelas (PTK) karena dilakukan untuk memecahkan masalah pembelajaran di kelas seperti yang dinyatakan Paizaluddin dan Ermalinda (2012) dan Enjah Taraki R. (2010). Tindakan diberikan guru atau dengan arahan guru yang akan dilakukan siswa. PTK termasuk penelitian deskriptif karena menggambarkan bagaimana suatu teknik pembelajaran diterapkan dan hasil yang diinginkan dapat dicapai.

Setiap siklus pada PTK dilaksanakan mulai dari perencanaan, tindakan, observasi, dan refleksi. Setiap siklus dilaksanakan dalam dua kali pertemuan. Jika pada siklus kedua tujuan belum tercapai maka dilanjutkan lagi ke siklus ketiga sampai tujuan tercapai. Materi pembelajaran mengacu matematika teknologi dan industri untuk SMK (Dedi Heryadi, 2006), (Kasmina, dkk, 2008).
Langkah-langkah penelitian dapat dilihat pada Gambar 1. Penelitian dimulai dari ide awal atau identifikasi masalah yang dilanjutkan dengan rumusan masalah, prosedur penelitian, setting dan subyek penelitian. Kemudian dilanjutkan dengan planning, action, observation, dan reflection.

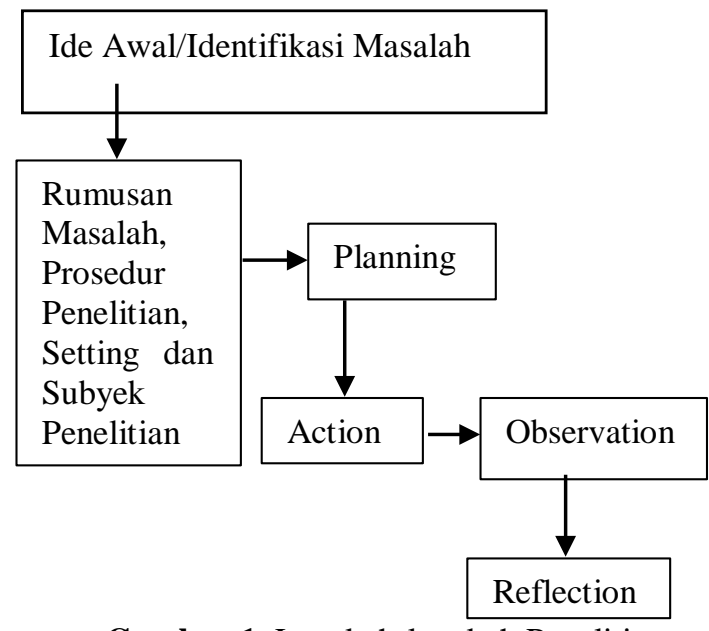

Gambar 1. Langkah-langkah Penelitian 


\section{$\pi$ (Phi)}

\section{Analisis Data}

Pengumpulan data penelitian didapatkan melalui observasi, angket (kuesioner), dan tes. Observasi bersamaan dengan pelaksanaan tindakan. Data yang dikumpulkan berisi tentang pelaksanaan tindakan dan rencana yang sudah dibuat serta dampaknya pada proses dan hasil instruksional yang dikumpulkan dengan alat bantu instrumen yang dikembangkan oleh peneliti. Observasi digunakan untuk memperoleh informasi aktivitas belajar dengan menggunakan model pembelajaran kooperatif tipe TAI.

Penelitian menggunakan angket berstruktur (berisi pertanyaan yang disertai pilihan jawaban) dalam memperoleh informasi efektivitas TAI. Tes adalah seperangkat rangsangan yang diberikan kepada seseorang untuk mendapatkan jawaban yang dijadikan penetapan skor angka.

Teknik analisis data dilakukan dengan reduksi data, penyajian data, dan penarikan kesimpulan. Reduksi data adalah melakukan seleksi dan mengolah data mentah menjadi informasi yang bermakna dari tes dan observasi yang telah dilakukan dengan tujuan mengetahui hasil belajar dan ketuntasan belajar siswa, baik secara individu maupun klasikal digunakan persamaan berikut:

$$
\mathrm{P}=\frac{\mathrm{S}_{\mathrm{i}}}{\mathrm{S}_{\mathrm{t}}} \times 100 \%
$$

Keterangan :

$\mathrm{P}=$ Daya serap perorangan

$\mathrm{S}_{\mathrm{i}}=$ Skor yang diperoleh siswa

$\mathrm{S}_{\mathrm{t}}=$ Skor maksimum siswa
Setelah data diolah, data disajikan dalam bentuk paparan naratif kemudian data yang disajikan tersebut kemudian disimpulkan keberhasilan atau kegagalan pelaksanaan tindakan yang telah dilakukan.

Penelitian ini dinyatakan berhasil apabila 80\% siswa kelas XI AP SMK Negeri 4 Pangkalpinang tahun 2016 mendapatkan nilai matematika tentang luas permukaan dan volume bangun ruang sisi datar telah mencapai KKM minimal 65,00.

\section{HASIL DAN PEMBAHASAN}

Data dalam penelitian ini berupa pengamatan penggunaan model pembelajaran kooperatif tipe TAI dan pengamatan aktifitas guru dan siswa pada setiap siklusnya. Data lembar observasi diambil dari pengamatan penggunaan TAI untuk mengetahui pengaruh dalam meningkatkan hasil belajar siswa dan data dari pengamatan aktivitas guru dan siswa. Data tes formatif untuk mengetahui peningkatan prestasi belajar siswa setelah digunakannya TAI.

\section{Hasil Belajar Pra Siklus}

Pra siklus dilakukan melalui tahap perencanaan, pelaksanaan, evaluasi, dan refleksi. Pada tahap perencanaan dilakukan dengan mempersiapkan RPP, soal tes, lembar observasi dengan model pembelajaran dan angket siswa. Pada tahap pelaksanaan, pembelajaran mengacu pada skenario pembelajaran dan RPP yang telah dipersiapkan. Materinya kubus dan balok. Di akhir pra siklus ini dilaksanakan kegiatan evauasi. Hasil pada tahap evaluasi dapat dilihat pada Tabel 2.

Tabel 2. Hasil Belajar Pra Siklus

\begin{tabular}{ccc}
\hline Uraian & Nilai/jumlah siswa & Keterangan \\
\hline Rata-rata nilai & 55,90 & Dari total 21 siswa \\
Nilai tertinggi & 100 & Ada 1 siswa \\
Nilai terendah & 10 & Ada 1 siswa \\
Siswa tuntas & 6 & $28,57 \%$ \\
Siswa tidak tuntas & 15 & $71,43 \%$ \\
\hline
\end{tabular}


Berdasarkan Tabel 2, kelas XI AP yang mencapai $\geq \mathrm{KKM}$ hanya sebanyak 6 siswa (28,57\%), sedangkan 15 siswa (71,43\%) belum mencapai KKM. Secara klasikal ketuntasan belajar belum mencapai yang dipersyaratkan yaitu minimal $80 \%$.

Pada tahap refleksi didapatkan didapatkan dua hal penting, yaitu:

1) Keaktifan belajar siswa rendah (64,94\%). Keberanian mengerjakan soal di depan dan untuk bertanya juga rendah. Perlu diterapkan model pembelajaran yang dapat meningkatkan keaktifan siswa.

2) Hasil belajar siswa masih jauh dari harapan sehingga perlu dilakukan pembimbingan baik dari guru maupun teman sejawat.

\section{Hasil Belajar Siklus 1}

juga dilakukan tahap perencanaan, pelaksanaan, evaluasi, dan refleksi. Tahap perencanaan dipersiapkan hal-hal berikut agar pelaksanaan dapat maksimal, yaitu:

1) Menyusun jadwal penelitian siklus 1 sebanyak dua kali pertemuan

2) Menyusun RPP dengan model pembelajaran kooperatif tipe TAI.

3) Menyusun Lembar Kerja Siswa (LKS)

4) Menyusun soal evaluasi

5) Menyusun lembar observasi dan angket.

6) Menyusun skenario pembelajaran

7) Guru menutup kegiatan pembelajaran

Tahap pelaksanaan pembelajaran mengacu pada skenario pembelajaran dan RPP yang telah dipersiapkan. Materinya limas dengan alas segitiga dan segiempat. Di akhir siklus 1 ini dilaksanakan juga evaluasi hasil belajar dengan hasil seperti pada Tabel 3.

Tabel 3. Hasil Belajar Siklus 1

\begin{tabular}{ccc}
\hline Uraian & Nilai/jumlah siswa & Keterangan \\
\hline Rata-rata nilai & 62,57 & Dari total 21 siswa \\
Nilai tertinggi & 100 & Ada 1 siswa \\
Nilai terendah & 26 & Ada 1 siswa \\
Siswa tuntas & 12 & $57,14 \%$ \\
Siswa tidak tuntas & 9 & $42,86 \%$ \\
\hline
\end{tabular}

Berdasarkan Tabel 3, kelas XI AP yang mencapai KKM terdapat 12 siswa (57,14\%). Ketuntasan belajar ini walaupun sudah meningkat dari pra siklus tetapi belum mencapai yang dipersyaratkan $80 \%$. Masih terdapat 9 siswa (42,86\%) yang belum mencapai KKM.

Tahap refleksi didapatkan hal-hal berikut:

1) Keaktifan belajar belum maksimal $(69,16 \%)$, keberanian mengerjakan soal di depan dan untuk bertanya juga masih rendah. Perlu diterapkan undian yang dapat meningkatkan keaktifan siswa.

2) Hasil belajar siswa masih belum sesuai yang diharapkan sehingga perlu dilakukan pembimbingan baik dari guru maupun teman sejawat.

\section{Hasil Belajar Siklus 2}

Pada siklus 2, tahap perencanaan dilakukan dengan mengacu pada refleksi siklus 1, pelaksanaan siklus 2 agar bisa mendapatkan hasil maksimal maka dipersiapkan hal-hal berikut:
1) Menyusun jadwal penelitian
2) Menyusun RPP dengan model pembelajaran kooperatif tipe TAI
3) Menyusun Lembar Kerja Siswa (LKS)
4) Menyusun soal evaluasi
5) Menyusun lembar observasi dan angket.
6) Menyusun skenario pembelajaran
7) Guru menutup kegiatan pembelajaran 
Tahap pelaksanaan pembelajaran dilakukan dengan mengacu pada skenario pembelajaran dan RPP yang telah dipersiapkan. Materinya adalah prisma alas segitiga dan segiempat. Di akhir siklus 2 ini dilaksanakan juga evaluasi hasil belajar dengan hasil seperti pada Tabel 4 .

Tabel 4. Hasil Belajar Siklus 2

\begin{tabular}{ccc}
\hline Uraian & Nilai/jumlah siswa & Keterangan \\
\hline Rata-rata nilai & 74,48 & Dari total 21 siswa \\
Nilai tertinggi & 96 & Ada 6 siswa \\
Nilai terendah & 30 & Ada 2 siswa \\
Siswa tuntas & 17 & $80,95 \%$ \\
Siswa tidak tuntas & 4 & $19,05 \%$ \\
\hline
\end{tabular}

Berdasarkan Tabel 4, kelas XI AP yang telah mencapai KKM sebanyak 17 siswa (80,95\%), sedangkan yang belum mencapai KKM ada 4 siswa (19,05\%). Persentase ketuntasan belajar secara klasikal telah meningkat dibanding siklus 1 dan telah melampaui $80 \%$.

Sebagai refleksi pada siklus 2 didapatkan hal-hal berikut:

1) Siswa sudah aktif $72,40 \%$, siswa berani mengerjakan soal di depan dan berani juga untuk bertanya.

2) Hasil belajar siswa telah sesuai yang dipersyaratkan $80 \%$ sehingga penelitian ini bisa dikatakan berhasil.

\section{Pembahasan}

\section{Ketuntasan Hasil Belajar Siswa}

Model pembelajaran kooperatif tipe TAI dapat meningkatkan hasil belajar siswa. Hal ini terlihat dari semakin meningkatnya pemahaman siswa terhadap materi yang disampaikan guru. Ketuntasan belajar meningkat dari pra siklus, siklus 1, dan siklus 2 yaitu 28,57\%, 57,14\% dan 80,95\%. Dari siklus 2 ini ketuntasan belajar siswa secara klasikal telah tercapai.

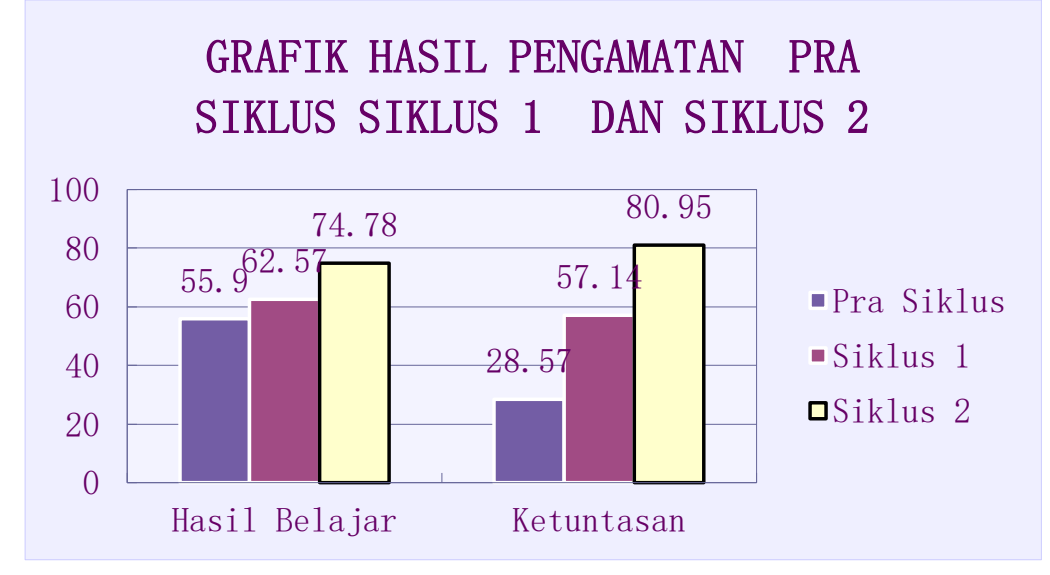

Gambar 2. Peningkatan hasil belajar

Peningkatan hasil belajar dari pra siklus, siklus 1, dan siklus 2 dalam bentuk grafik dapat dilihat seperti pada Gambar 2. Kenaikan hasil belajar siswa secara klasikal dari pra siklus ke siklus 1 tergolong rendah
(6,67\%) karena siswa baru pertama kali melaksanakan model pembelajaran kooperatif tipe TAI sehingga banyak siswa masih merasa bingung dan belum paham apa yang seharusnya dilakukan. 


\section{$\pi$ (Phi)}

Dari siklus 1 ke siklus 2 kenaikan hasil belajar siswa secara klasikal tergolong tinggi $(23,81 \%)$ sebab siswa sudah mulai terbiasa dengan model pembelajaran kooperatif tipe TAI. Pada siklus 2 ini siswa terlihat senang dalam kegiatan pembelajaran. Siswa aktif dalam pembelajaran dan berani bertanya tentang materi yang belum dipahaminya. Selain itu undian dapat memotivasi siswa untuk menguasai materi. Siswa harus selalu siap dengan jawaban hasil belajar kelompoknya.

Hasil belajar siswa meningkat, ketuntasannya juga meningkat. Dari pra siklus siswa yang tuntas 6 siswa, siklus 1 menjadi 12 siswa dan siklus 2 mencapai 17 siswa. Dari siklus 2 ini siswa yang tuntas belajarnya $80,95 \%$. Persentase ketuntasan siswa ini sudah sesuai dengan target yang telah ditetapkan yaitu $80 \%$.

\section{Aktivitas dalam Pembelajaran}

Model pembelajaran kooperatif tipe TAI dapat membuat siswa lebih senang. Siswa tidak lagi bosan, tegang, takut bahkan tidak lagi menganggap matematika pelajaran yang sulit. Kerja sama antar siswa dapat membantu siswa yang belum paham menjadi paham.

\section{SIMPULAN DAN SARAN}

Model pembelajaran kooperatif tipe TAI mendapat tanggapan siswa, sikap dan inisiatif belajar dalam kelompoknya yang dapat meningkatkan keaktifan dan kegairahan belajar siswa. Peningkatan keberhasilan belajar matematika tentang luas permukaan dan volume bangun ruang sisi datar adalah dari 12 siswa yang tuntas siklus 1 menjadi 17 siswa yang tuntas pada siklus 2 dari total seluruh 21 siswa.

Saran perbaikan kedepan adalah guru hendaknya berusaha memahami akan kesulitan belajar siswa. Model pembelajaran kooperatif tipe TAI adalah salah satu model pembelajaran, perlu dikembangkan modelmodel pembelajaran lain yang sesuai dengan
Jurnal Pendidikan Matematika Volume 5 Nomor 2 Tahun 2021 karakteristik materi yang diberikan. Guru matematika hendaknya dapat menerapkan model pembelajaran kooperatif tipe TAI ini untuk materi matematika yang lainnya.

\section{DAFTAR PUSTAKA}

Dedi Heryadi. (2006). Matematika Teknologi dan Industri untuk 3 SMK. Jakarta. Yudhistira.

Enjah Taraki R. (2010). Penelitian Tindakan Kelas. Bandung: PT Genesindo

Kasmina. Dkk. (2008). Matematika Program Keahlian Teknologi, Kesehatan dan Pertanian untuk SMK dan MAK Kelas XI. Jakarta. Erlangga

Paizaluddin dan Ermalinda. (2012). Penelitian Tindakan Kelas

(Classroom Action Research) Panduan Teoritis dan Praktis. Bandung: Alfabeta

Pupuh Fathurrohman dan M. Sobry Sutikno. (2010). Strategi Belajar Mengajar "Strategi Mewujudkan Pembelajaran Bermakna Melalui Pemahaman Konsep Umum dan Konsep Islami. Bandung: PT Refika Aditama

Suyatno. (2009). Menjelajah Pembelajaran Inovatif. Sidoarjo: Masmedia Buana Pustaka 